Journal of Applied Fluid Mechanics, Vol. 7, No. 2, pp. 299-313, 2014.

Available online at www.jafmonline.net, ISSN 1735-3572, EISSN 1735-3645.

DOI: $10.36884 / \mathrm{jafm} .7 .02 .19569$

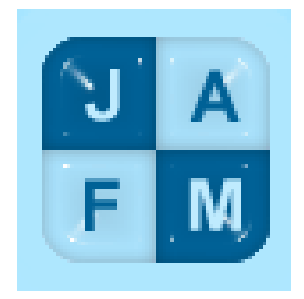

\title{
A Modeling Study of Boundary Layer Wind Flow over Tehran Region during a High Pollution Episode
}

\author{
H. Malakooti ${ }^{1 \dagger}$ and A. A. Bidokhti ${ }^{2}$ \\ ${ }^{1}$ Atmospheric and Oceanic Environmental Modeling Laboratory [AOEML], Faculty of Atmospheric and \\ Oceanic Science and Technology, University of Hormozgan, P.O. Box: 3995, Bandar Abbas, Iran \\ ${ }^{2}$ Institute of Geophysics, University of Tehran, P.O. Box: 14155-6466, Tehran, Iran \\ $\dagger$ Corresponding Author Email: malakooti@ hormozgan.ac.ir
}

(Received February 24, 2012; accepted June 27, 2013)

\begin{abstract}
The influence of a mega-city on the atmospheric boundary layer wind field was examined in the complex-terrain, semi-arid Tehran region using the Pennsylvania State University/National Center for Atmospheric Research fifth-generation Mesoscale Model (MM5) during a high pollution period. In addition, model sensitivity studies were conducted to evaluate the performance of the urban canopy and urban soil model "SM2-U (3D)" parameterization on the wind field. The topographic flows and urban effects were found to play important roles in modulating the wind field, and the urbanized areas exerted important local effects on the boundary layer meteorology. An emission inventory of heat generation was developed and updated for 2005 in this work. By using a detailed methodology, we calculated spatial and temporal distributions of the anthropogenic heat flux $\left(\mathrm{Q}_{f}\right)$ for Tehran during 2005. Wintertime $\mathrm{Q}_{\mathrm{f}}$ is found larger than summertime $\mathrm{Q}_{\mathrm{f}}$, which reflects the importance of heating emissions from buildings and traffic during cold and warm periods respectively. Different urban parameterizations were used as a tool to investigate the modifications induced by the presence of an urban area in the area of interest. It is found that, for local meteorological simulations, the drag-force approach (DA) coupled with an urban soil model (SM2-U) is preferable to the roughness approach (RA) coupled with a slab soil model. The comparisons indicated that the most important features of the wind field, in urban areas are well reproduced by the DA-SM2-U configuration with the anthropogenic heat flux being taken into account. This modeling option showed that the suburban part of the city is dominated by topographic flows whereas the center and south of Tehran are more affected by urban heat island (UHI) forcing especially during the night in studied episodes.
\end{abstract}

KEYWORDS: Heat island, Topographic flow, Urban canopy model, Urban soil model, Anthropogenic heat flux

\section{NOMENCLATURE}

$<\quad \quad$ Reynolds averaged variables

$a, b \quad$ coefficients of Fourier series fitting function

$A_{p} \quad$ canopy plan area density

$A_{\theta} \quad$ heat source from the anthropogenic heat flux $\left(\mathrm{K} \cdot \mathrm{kg} \cdot \mathrm{m}^{-3} \cdot \mathrm{s}^{-1}\right)$

$D C \quad$ daily consumption

$D_{E}^{j} \quad$ E wake production term $\left(\mathrm{m}^{2} \cdot \mathrm{s}^{-3}\right)$

$D_{q} \quad$ humidity sources from buildings and vegetation $\left(\mathrm{kg} \cdot \mathrm{gr} \cdot \mathrm{m}^{-4} \cdot \mathrm{gr}^{-1}\right)$

$D_{u i}{ }^{j} \quad$ momentum sources due to the presence of the canopy vertical surfaces $\left(\mathrm{kg} \cdot \mathrm{m}^{-4} \cdot \mathrm{s}^{-2}\right)$

$D_{\theta} \quad$ sensible heat sources from buildings and the vegetation $\left(\mathrm{K} \cdot \mathrm{kg} \cdot \mathrm{m}^{-3} \cdot \mathrm{s}^{-1}\right)$ turbulence kinetic energy $\left(\mathrm{m}^{2} \cdot \mathrm{s}^{-2}\right)$ number of vehicles fractional consumption profile fuel economy $\left(\mathrm{km} \cdot \mathrm{lit}^{-1}\right)$ shear production by the building horizontal surfaces $\left(\mathrm{m}^{2} \cdot \mathrm{s}^{-3}\right)$

fraction of the surface type momentum sources due to the presence of horizontal surfaces of buildings $\left(\mathrm{kg} . \mathrm{m}^{-4} \mathrm{~s}^{-2}\right)$

$\begin{array}{ll}H_{E} & \text { E buoyancy production by } D_{\theta} \text { and } A_{\theta} \\ \left(\mathrm{m}^{2} \cdot \mathrm{s}^{3}\right) & \end{array}$

$\begin{array}{ll}H_{E} & \text { E buoyancy production by } D_{\theta} \text { and } A_{\theta} \\ \left(\mathrm{m}^{2} \cdot \mathrm{s}^{3}\right) & \end{array}$ Hes heat release in any sector by electricity 


\begin{tabular}{|c|c|}
\hline & consumption $(\mathrm{J})$ \\
\hline$H_{\text {link }}$ & anthropogenic heat release in any link $(\mathrm{J})$ \\
\hline$H P R$ & heating production rate \\
\hline$i$ & index of vehicle category \\
\hline$j$ & index for number of vehicles \\
\hline$i, j$ & index for surface type \\
\hline$k$ & level above the ground inside canopy \\
\hline$k_{e x}$ & radiation extinction coefficient \\
\hline$k_{\text {top }}$ & level in top of canopy \\
\hline$l$ & Turbulent length $(\mathrm{m})$ \\
\hline$l_{B L}$ & boundary layer Turbulent length (m) \\
\hline$l_{\text {can }}$ & canopy layer Turbulent length (m) \\
\hline$n$ & $\begin{array}{l}\text { harmonic number of Fourier series fitting } \\
\text { function }\end{array}$ \\
\hline $\mathrm{NHC}$ & net heat of combustion $\left(\mathrm{J} \mathrm{kg}^{-1}\right)$ \\
\hline$p$ & street canyon top level \\
\hline$Q_{f}$ & anthropogenic heat flux (w. $\mathrm{m}^{-2}$ ) \\
\hline$q_{w}$ & total water content $\left(\mathrm{gr} \mathrm{gr}^{-1}\right)$ \\
\hline$R_{G}$ & direct and diffused solar radiation $\left(\mathrm{w} \cdot \mathrm{m}^{-2}\right)$ \\
\hline$R_{n}$ & net radiation flux $\left(\mathrm{w} \cdot \mathrm{m}^{-2}\right)$ \\
\hline$R_{q}$ & $\begin{array}{l}\text { general forcing terms in the total water } \\
\text { content equation }\left(\mathrm{kggr} \cdot \mathrm{m}^{-4} \mathrm{gr}^{-1}\right)\end{array}$ \\
\hline$R_{u i}$ & $\begin{array}{l}\text { general forcing terms in the momentum } \\
\text { equation }\left(\mathrm{kg} . \mathrm{m}^{-4} \mathrm{~s}^{-2}\right)\end{array}$ \\
\hline$R_{\theta}$ & $\begin{array}{l}\text { general forcing terms in the liquid-water } \\
\text { potential } \\
\left(\mathrm{Kkg} \cdot \mathrm{m}^{-3} \mathrm{~s}^{-1}\right)\end{array}$ \\
\hline surf & top area density \\
\hline$T$ & temperature $(\mathrm{K})$ \\
\hline
\end{tabular}

\section{INTRODUCTION}

The planetary boundary layer (PBL) structure and its evolution play a major role in the physical and chemical processes related to air pollution formation and dispersion in the atmosphere. Local thermally driven mesoscale circulations and flows such as sea breezes, topographic flows and urban heat island (UHI) circulation can have significant effects on local weather, the diurnal evolution of the boundary layer structure and pollutant transport, particularly under synoptic anticyclonic conditions. The effects and interactions of two local thermally driven processes, topographic flows and UHI under different meso-scale and synoptical conditions play an important role in the Tehran region's weather.

In valley cities and during calm periods, meteorological conditions may lead to critical air quality problems due to low horizontal ventilation especially during transition between slope flows in early morning and in the late afternoon (Whiteman, 2000) and due also to the combination of slope winds with the urban heat island, especially during winter and night time, when vertical diffusion is small (Atkinson, 1981).

Urbanization is often associated with surface temperature anomalies such as the UHI and the oasis effect. Changes in local and regional atmospheric processes associated with urbanization are complex and difficult to generalize (Oke, 1982), but we now have the computational and observational tools to explore how particular urbanization scenarios affect meteorology and climate. Atkinson (2003) ran sensitivity studies using a numerical

\begin{tabular}{|c|c|}
\hline$t$ & time (s) \\
\hline$T s$ & surface temperature $(\mathrm{K})$ \\
\hline$U$ & $\begin{array}{l}\text { simulated horizontal zonal wind } \\
\text { component }\left(\mathrm{m}^{-1} \mathrm{~s}^{-1}\right)\end{array}$ \\
\hline$u_{i}$ & horizontal wind speed component $\left(\mathrm{m} . \mathrm{s}^{-1}\right)$ \\
\hline$U_{O}$ & observed zonal wind component $\left(\mathrm{m} \cdot \mathrm{s}^{-1}\right)$ \\
\hline$V$ & $\begin{array}{l}\text { simulated meridional wind component } \\
\left(\mathrm{m} \cdot \mathrm{s}^{-1}\right)\end{array}$ \\
\hline$V$ & traffic velocity $\left(\mathrm{m} \cdot \mathrm{s}^{-1}\right)$ \\
\hline$V_{O}$ & $\begin{array}{l}\text { observed meridional wind component } \\
\left(\mathrm{m} . \mathrm{s}^{-1}\right)\end{array}$ \\
\hline$V W D$ & vector wind difference $\left(\mathrm{m} \cdot \mathrm{s}^{-1}\right)$ \\
\hline$W_{E}^{j}$ & E accelerated cascade term $\left(\mathrm{m}^{2} \cdot \mathrm{s}^{-3}\right)$ \\
\hline$Z_{e}$ & zenith angle \\
\hline$\alpha$ & surface albedo \\
\hline$\Delta \mathrm{t}$ & time interval (s) \\
\hline$\Delta \mathrm{z}$ & thickness of Layer (m) \\
\hline$\varepsilon$ & surface emissivity \\
\hline$\varepsilon_{\mathrm{a}}$ & air emissivity \\
\hline$\theta_{L}$ & liquid-water potential temperature $(\mathrm{K})$ \\
\hline$\rho$ & air density (kg.m-3) \\
\hline$\rho_{f}$ & fuel density $\left(\mathrm{kg} \mathrm{l}^{-1}\right)$ \\
\hline$\sigma$ & Stefan-Boltzmann constant \\
\hline$\Phi$ & either the multiple fluxes $\left(\mathrm{w} \cdot \mathrm{m}^{-2}\right)$ \\
\hline$\Phi^{*}$ & $\begin{array}{l}\text { flux has been modified to consider the heat } \\
\text { repartition inside the canyons }\left(\mathrm{w} \cdot \mathrm{m}^{-2}\right)\end{array}$ \\
\hline$\Psi$ & sky view factor \\
\hline
\end{tabular}

model of an idealized urban area configured to represent London, England. Among the various possible contributors to UHI (albedo, anthropogenic heat, emissivity, roughness length, sky view factor, surface resistance to evaporation, and thermal inertia), surface resistance to evaporation was the most important factor controlling heat island strength during the day, while anthropogenic heating dominated at night. The magnitude of the urbanization impact on climate is sensitive to both the local climate regime and to various urban parameters. It remains a major research challenge to determine how, in various situations, urbanization interacts with other local forcing factors.

Climate, terrain, and land-surface contrasts make Tehran Mega-City (TMC) a unique laboratory for studying PBL development in complex terrain. The principal highland regions of the Tehran province are the Alborz mountain in the north and the Kavir desert in the south east. Tehran lies in a valley, situated south of the Alborz mountain range that crosses the north part of Iran (Fig. 1). It is located at $35.7^{\circ} \mathrm{N}$ and $51.4^{\circ} \mathrm{E}$. The TMC is $45 \mathrm{~km}$ long and $30 \mathrm{~km}$ wide with a valley bottom elevation of $\sim 1050$ to $1800 \mathrm{~m}$ above mean sea level (MSL). It means that the average slope is 0.026 in the north-south direction. The surrounding topography rises to as high as $3000-3700 \mathrm{~m}$ MSL in $\sim 7 \mathrm{~km}$ toward north and about 1800-2200 m MSL in $\sim 10 \mathrm{~km}$ toward east and south-east. Several deep and narrow valleys enter the TMC from the Alborz mountains to the south and wide narrow valleys to the south-west. More than 10 million people live within and adjacent to the TMC in this valley, which includes with urban, residential, and agricultural land covers. These topography and land-surface contrasts produce a great 
variety of flows, although their characteristics vary with season and synoptic situation. The TMC has a semi-arid climate with mean annual precipitation (MAP) of 230 $\mathrm{mm}$. The prevailing synoptic wind is generally from the west in TMC, but combination of high terrain, urbanization and weak synoptic forcing can lead to weak and variable winds with complex circulation patterns in this area.

According to this summary and routine measurements (see Fig. 2) and researches, topographic flows are dominated over north and east of TMC and west and south of TMC show some lower frequency in the diurnal cycling of wind direction (e. g. JICA, 1997). The main observations show strong time variations and wind observations show semi-periodic oscillations during both night and day with periods typically longer than 40 minutes that could be due to internal waves induced by drainage flows at night, instability of the upslope flow during the day (Bidokhti and Noroozi, 2004). Layers of different temperature and wind speed/direction characterize the vertical structure of the flow. The formation of such layers in TMC may occur due to different air masses of disparate densities originating at slopes of different orientations surrounding the air basin. This formation is similar to that observed on an eastern slop of the Salt lake basin during the Vertical Transport and Mixing Experiment (VTMX) and we have the same interpretation as Monti et al. (2002) for this case.

\section{Material AND Methods}

The model used in this study is the standard version of the fifth-generation Pennsylvania State UniversityNational Center for Atmospheric Research Mesoscale Model (MM5; Grell et al. 1994) and a modified parameterization of MM5 that is called DA-SM2-U (Dupont et al., 2004). DA-SM2-U includes some improvements that are able to simulate all meteorological fields within and above the rural and urban canopies. The DA-SM2-U parameterization uses the DA approach to represent the dynamic and turbulent effects, (i) of the buildings following the work of Lacser and Otte (2002) and Martilli et al. (2002), and (ii) of the vegetation (Dupont et al., 2004). The DA is developed inside the $E$ - $l$ Gayno-Seaman planetary boundary layer (GSPBL) model (Shafran et al., 2000). The DA is coupled with a modified version of the soil model SM2U (Dupont and Mestayer, 2006 ; Dupont et al., 2006), which is capable of determining the heat fluxes and surface temperatures in each in-canopy computational cell following the vertical distribution of the vegetation and buildings. In addition, it takes into account different detailed processes such as shadowing effects, radiative trapping inside street canyons, heat storage, vegetation transpiration, evaporation from the bare soil and from the water intercepted by the canopy elements, etc. The lower level of the computational domain corresponds to the real level of the ground, and additional vertical layers are included within the canopy to allow more detailed meteorological fields within the roughness sub-layer (RSL).
DA-SM2-U modifications have been implemented inside two main parts of MM5:

- MM5 GSPBL scheme by modification of the conservation equations and turbulence length (Eq. (1), Eq. (2), Eq. (3), Eq. (4) and Eq. (5)).

Inside the canopy, the effects of buildings and vegetation are represented by adding i) in the dynamic equation, a friction force induced by horizontal surfaces of buildings, and a pressure and viscous drag force induced by the presence of buildings and vegetation, ii) in the temperature equation, the sensible heat fluxes due to buildings and vegetation, and the anthropogenic heat flux parameterized following section 2.1.2, iii) in the specific humidity equation, the humidity sources coming from the evapotranspiration of the vegetation and the evaporation of the water intercepted by buildings, and iv) in the turbulent kinetic energy equation, a shear production terms induced by horizontal surfaces of buildings, turbulent kinetic energy sources induced by the presence of buildings and vegetation, and buoyant production terms from the sensible heat fluxes emitted by buildings and vegetation. The turbulence length scale has been also modified inside the urban canopy, as proposed by Martilli et al. (2002), by adding a second length scale to consider the vortices induced by the presence of buildings; this modification has been also extended to the vegetation. All of these new terms are volumetric: the volume of buildings is considered in each cell whereas the volume of the vegetation is neglected. The turbulent transport in the vertical direction is also modified to consider the real volume of air in the cell.

$$
\begin{aligned}
& \frac{\partial \rho<u_{i}>}{\partial t}=R_{u i}+F_{u i}^{b u i}+\sum_{j} D_{u i}^{j} \\
& \frac{\partial \rho\left\langle\theta_{L}\right\rangle}{\partial t}=R_{\theta}+D_{\theta}+A_{\theta} \\
& \frac{\partial \rho\left\langle q_{w}\right\rangle}{\partial t}=R_{q}+D_{q} \\
& \frac{\partial E}{\partial t}=F_{E}^{b u i}+H_{E}+\sum_{j} W_{E}^{j}-\sum_{j} D_{E}^{j} \\
& \frac{1}{l(k)}=\frac{1}{l_{B L}(k)}+\frac{1}{l_{c a n}(k)}
\end{aligned}
$$

- Soil model SM2-U by modification of the surface canopy heat fluxes and ground equations (e.g. Eq. 6, Eq. 7 and Eq. ${ }^{\wedge}$ ).

DA-SM2-U (3D) is a multi-layer canopy and soil model with few layers of a couple meters within the canopy depending on the mesh of the mesoscale model domain, and three layers within the ground: a surface soil layer for the natural surfaces, a root zone layer, and a deep soil layer. This simple discretization of the ground allows the model to estimate the soil humidity available for the evapotranspiration with a good compromise between the computational time and the accuracy of the water budget evaluation. The sub-grid land coverage variability is introduced in DA-SM2-U by considering eight surface types in each canopy grid cell. The total heat flux for a canopy grid cell is thus determined by the average of 
individual heat fluxes calculated for each surface type, weighted by the fraction areas within the cell. In DASM2-U, the building wall effects are included through the equation of the paved surface temperature by introducing the heat stored by building walls, and by modelling the radiative trapping with an effective street canyon albedo parameterisation deduced from Masson (2000). The net radiation within the canopy is assumed to exponentially decay toward the ground as extended by Brown (2000) to the urban canopy. The heat fluxes from the street canyons are assessed through the paved surfaces, by considering a vertical distribution of the tops of the street canyons. The sensible and net radiative fluxes assessed at the top of the street canyons are distributed inside the street following the sky view factor of the walls and of the street floor.

$$
\begin{aligned}
& \Phi_{\text {mean }}(k)=\sum_{j} f_{j} \operatorname{Surf}_{j}(k) \Phi_{j}(k)+f_{p a v} \Phi_{p a v}^{*}(k) \\
& R_{n j}(k)=\left[\left(1-\alpha_{j}\right) R_{G}\left(k_{t o p}\right)-\varepsilon_{j} \sigma\left(T_{s j}(k)^{4}-\varepsilon_{a} T(k+1)^{4}\right)\right] \\
& \times \exp \left[\frac{\left.-k_{e x} \sum_{p=k+1}^{k_{\text {wpp }}}\left[\sum_{i} f_{i} A_{p i}(p)\right] \Delta z(p)\right]}{\left|\cos Z_{e}\right|}\right] \\
& \phi_{p a v}^{*}(k)=\frac{2 \Delta z(k) \Psi_{w \rightarrow s}(p, k)}{\sum_{t=1}^{p-1}\left[2 \Delta z(t) \Psi_{w \rightarrow s}(p, t)\right]+W(p) \Psi_{r \rightarrow s}(p, 0)} \phi_{p a v}(p)
\end{aligned}
$$

In order to view detail formulation and modifications you can see Dupont et al. (2004), Dupont and Mestayer (2006) and Dupont et al. (2006).

\subsection{Input Data}

In RA-SLAB (standard version), there is a single urban category defined from the U.S. Geological Survey (USGS) 24-category database. By comparing Tehran landuse data from available geographic information system (GIS) database, urban landuse defined by WRF preprocessing system (WPS) and terrain module of MM5 model, we considered a bigger area for Tehran than the terrain module urban landuse. Several geometrical parameters used by DA-SM2-U have been calculated using the integrated building, vegetation, and land use datasets such as mean building and vegetation heights, building and vegetation plan area density, building rooftop area density, vegetation top area density, building and vegetation frontal area density, wall-to-plan area ratio and building height-to-width ratio. In addition to the parameters listed above, numerous other parameters describing building and vegetation morphology and surface cover properties such as roughness lengths, drag-force coefficient, albedo, emissivity, volumetric heat capacity and thermal conductivity for all surface types are necessary. For applying anthropogenic heat flux inside urban canopy energy balance, one can divide this flux into several parts, such as heat release in canyons (by traffic, street lighting etc), roof stakes, open area and part that is released inside buildings in order to generate spatial and temporal distribution of $\mathrm{Q}_{\mathrm{f}}\left(\mathrm{W} \mathrm{m}^{-2}\right)$.

\subsubsection{Urban canopy parameterization}

For DA-SM2-U parameterization, six urban subcategories have been roughly constructed to cover the urban area following our simple classification, as represented in Fig. 3. Each of these urban sub-categories is characterized by the surface density of buildings and buildings mean height (see Table 1) for urban canopy parameterization (UCP). All physical properties of artificial surfaces are the same in each urban subcategory: buildings are represented with a) clay blocks wall-one way concrete block roof $(60 \%)$, b) old brick wall - brick arch roof (40\%), and with a horizontal section equal to $100 \mathrm{~m}^{2}$, and paved surfaces are made with asphalt. For DA-SM2-U, the vertical distributions of buildings and vegetation have been constructed following their average height and the shaped profiles similar to that used by Dupont et al. (2004). A mean vegetation height has been assigned for each of the USGS categories. It is assumed that the vertical distribution of the street canyon tops is identical to the roof vertical distribution.

\subsubsection{Heat Emission Inventory}

The population consumes energy in two main sectors: traffic and building sectors. Emissions due to human metabolism should also be considered although they are likely to be smaller. Vehicular traffic heat emissions are distributed spatially according to the street network and heat emissions from buildings can be divided into several subcategories such as residential, commercial, industrial, etc. The reasons for this classification include different behavior of consumption and different methods for estimating heat flux in each subcategory. We summarized the building sector according to 10 subcategories by merging some similar landuse classes from 24 landuse classes available in our primary GIS database.

In order to obtain accurate estimations of the anthropogenic spatial patterns for mega-cities similar to Tehran, it is desirable to develop a high resolution GIS database for key parameters and subsequent calculations. In this study, various types of consumption data are converted to a GIS format in each district for traffic, Natural gas (NG) and electricity. The computational domain has a $500 \mathrm{~m}$ resolution and covers an area of $60 \times 45 \mathrm{~km}^{2}$. Because all components do not have the same height of release, it is disable to define a vertical profile and depth in order to generate vertical $\mathrm{Q}_{\mathrm{f}}$ distribution.

In order to estimate the heat released from vehicles, we have used information from the database on traffic links and nods of the Tehran road network inside EMME/2 model (Equilibre multimodal/multimodal equilibrium Version 2). It is desirable to obtain accurate key parameters for each vehicle category, its distribution of consumed fuels, mean fuel economies (FE: $\mathrm{km} \mathrm{l}^{-1}$ ) and some fuel chemical-physical properties such as, fuel density $\left(\rho_{\mathrm{f}}: \mathrm{kg} \mathrm{l}^{-1}\right)$ and mean net heat of combustion (NHC: $\mathrm{MJ} \mathrm{kg}^{-1}$ ) for the period of the studied episode. 
The approach used here presents some similarity to that used by Grimmond (1992) and Sailor and $\mathrm{Lu}$ (2004), however, it is formulated in order to take advantage of the output from the traffic model and available data from the Tehran Comprehensive Transportation and Traffic Studies Company (TCTTSC). With the values of traffic velocity $(\mathrm{V}: \mathrm{m} / \mathrm{s})$ and vehicle number by category ( 1 to 11 ), one can calculate the bulk anthropogenic heat release in any link by time interval ( $\Delta T: \mathrm{s})$ as follows:

$$
H_{\text {Link }}=\sum_{i=1}^{11} \sum_{j=1}^{f_{i}} \frac{V_{i j} \times \Delta T \times N H C_{i j} \times \rho_{f_{i j}}}{F E_{i j}(V)}
$$

where $f_{i}$ is the number of vehicles in each category (i), so that one can use fuel economy data $\mathrm{FE}(\mathrm{V})$ with this approach. In this study, all links are considered flat and the effect of slope on $\mathrm{FE}(\mathrm{V})$ is neglected.

In order to develop an accurate diurnal and monthly variability of electricity consumption in Tehran, we used an hourly digital database derived from scanning of available electrical division posts. These hourly consumption data are archived by Tehran Province Regional Electricity Company (TREC)'s Consumption Management Administration. To generate consumption profiles for all subcategories, we used the following time-varying function that modules diurnally by means of a Fourier series fitting function.

$$
\left.F(t)\right|_{e}=a_{0}+\sum_{i=1}^{n}\left[a_{i} \cos \left(\frac{2 n \pi t}{24}\right)+b_{i} \sin \left(\frac{2 n \pi t}{24}\right)\right]
$$

where $a_{i}, b_{i}$ and $n$ are estimated from data fitting. The number of harmonics $n$ equals 3 is sufficient to give a valid fitting. With electricity consumption function, daily electricity consumption (DC) $)_{\mathrm{e}}$ and heating production rate (HPR) for each sector, one can calculate the total heat release in any sector and in one hour by

$$
H_{e s}=[(D C)(H P R) F(t)]_{e s}
$$

We used HPR equals 0.9 , because about $10 \%$ of electricity is lost during transmission (Khan and Simpson, 2001). The next step is to calculate the spatial distribution of this heat flux. To that end, we use population density following Sailor and Lu (2004) for the residential subcategory. For the other subcategories, we used category-specific information about consumption and its diurnal profiles.
NG is the dominant heating fuel in Tehran building sectors (more than 96\%). We tested both the diurnal temperature profile formulation and the daily maximum and minimum temperature formulation (Sailor et al., 1998; Sailor and Lu, 2004) in order to generate average daily NG load curve in Tehran. We found some differences between the estimated profiles from observations (with some approximations) and the generated profiles from these formulations. Recent intensive experimental studies show that the hourly load curves for city-gas consumption do not follow exactly the outdoor temperature (Ueno, 2006) and do not show a main peak of consumption in early morning. For example, in Tehran, the main peak is observed near midnight in winter. Finally, we used a time-varying NG consumption profile that modules diurnally using Fourier fitting of observations (similar method as that used for electricity component), HPR equal 0.8 (on the other hand thermal combustion efficiency in this case) and nominal heating value for NG of $8250 \mathrm{kcal}$ per cubic meter from TGC analysis and measurements. We considered that $60 \%$ of the gross energy in the fuel is lost as waste heat at power plants. We used the same method for developing the spatial distribution of this component as for the electricity component.

The method used for estimation of metabolism heat flux is similar to that used by Sailor and $\mathrm{Lu}$ (2004) and uses a profile for metabolic rate.

Wintertime $Q_{f}$ is larger than summertime $Q_{f}$ with values of 20-25 Wm${ }^{2}$. According to the results of this study, we find that in the urban core region, all components of $\mathrm{Q}_{\mathrm{f}}$ can show maximum values and $\mathrm{Q}_{\mathrm{f}}$ can be 4-7 times the magnitude of the city-wide values. Fig. 4 and Fig. 5 present the results of the heat flux budget developed in this study and shows the spatial distribution of the daily mean $\mathrm{Q}_{\mathrm{f}}$ in Tehran region.

\section{Model Configuration}

The coupling of DA with SM2-U (3D), is tested in the Tehran basin, during 2-8 December 2005 (three episodes as long as three days with one day overlap). The five nested computational domains use $81,27,9,3$ and $1 \mathrm{~km}$ horizontal grid spacing. The standard version of MM5 was run in a one-way nested configuration for three outer domains by applying multiscale four-dimensional data assimilation (FDDA) as in Stauffer and Seaman (1994). 

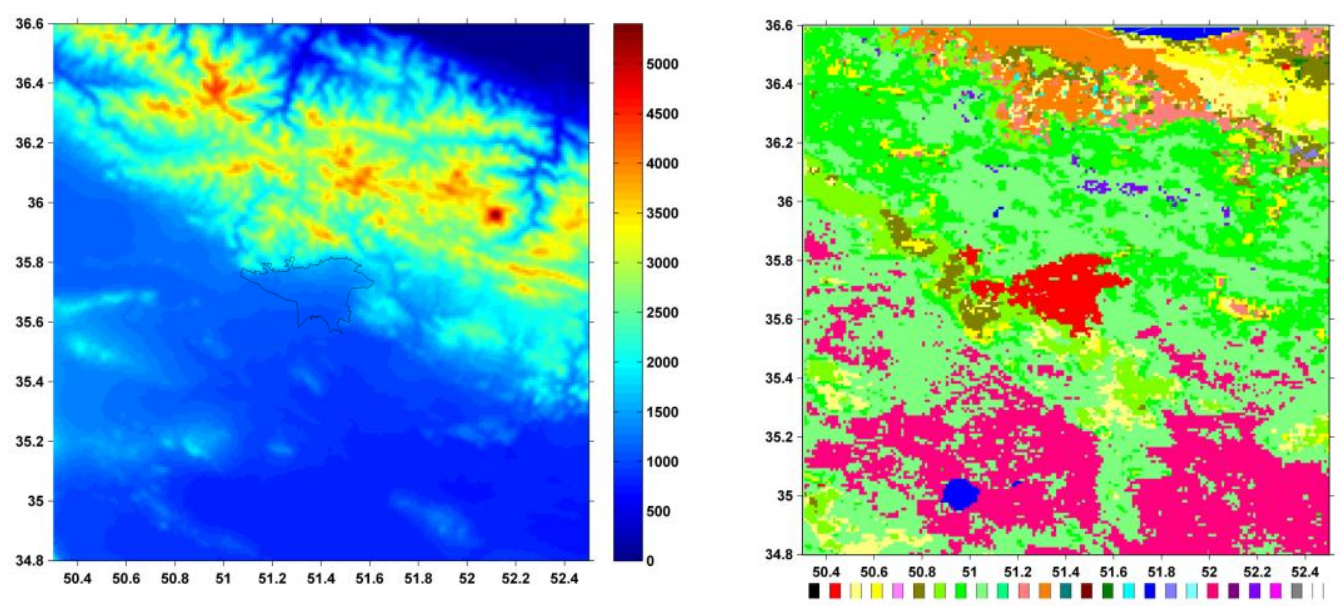

Fig. 1. Topography (left) and landuse distribution (right) in Tehran region (400 km x $400 \mathrm{~km}$ ) (1: Urban, 2: Drylnd Crop. Past., 3: Irrg. Crop. Past. 4:Mix. Dry/Irrg.C.P., 5: Crop./Grs. Mosaic, 6: Crop./Wood Mosc, 7: Grassland, 8: Shrubland, 9: Mix Shrb./Grs., 10: Savanna, 11: Decids. Broadlf., 12: Decids. Needlf., 13: Evergrn. Braodlf., 14: Evergrn. Needlf., 15: Mixed Forest, 16: Water Bodies, 17: Herb. Wetland, 18: Wooded wetland, 19: Bar. Sparse Veg., 20: Herb. Tundra, 21: Wooden Tundra, 22: Mixed Tundra, 23: Bare Grnd. Tundra, 24: Snow or Ice and 0: No data).

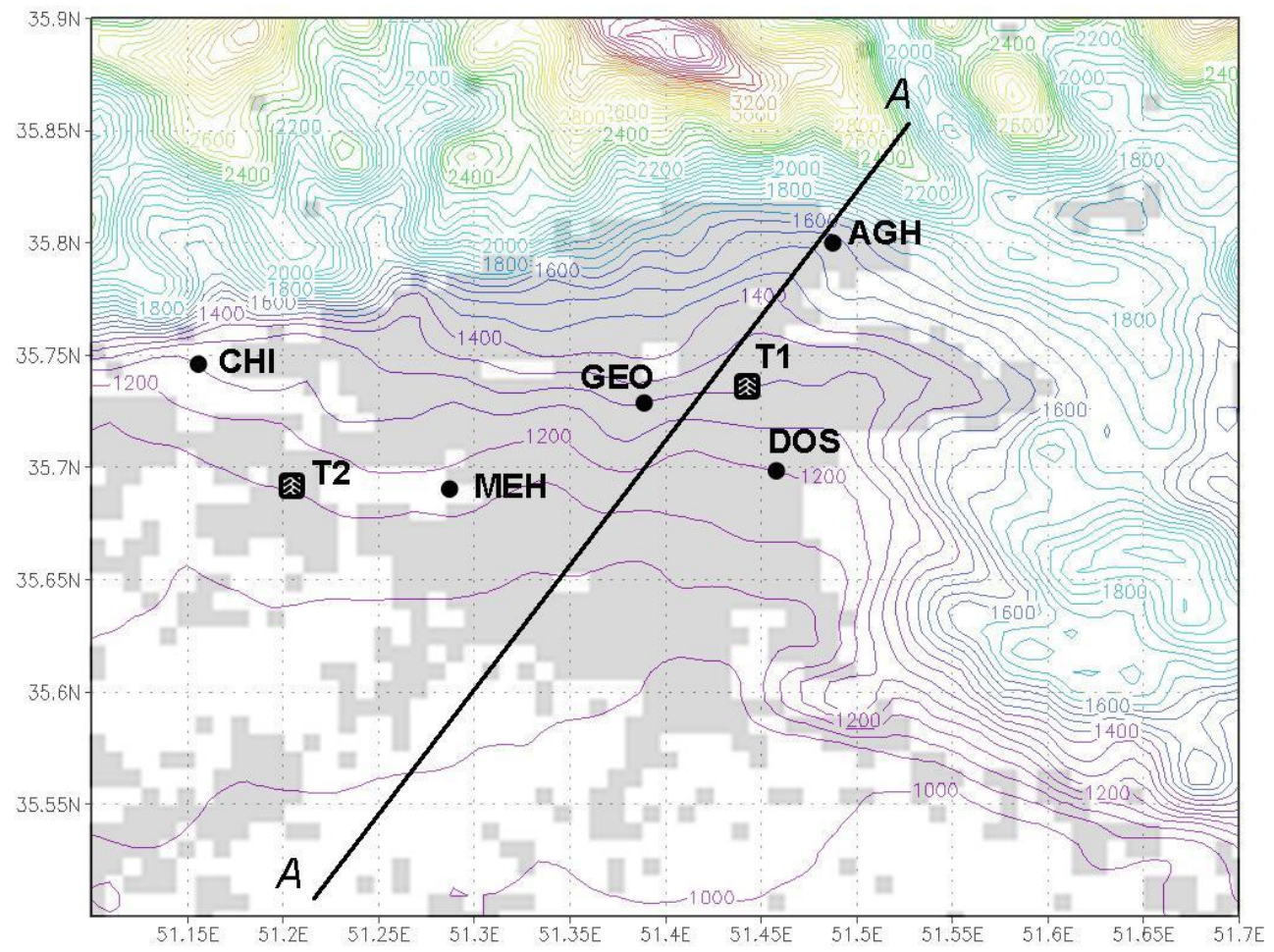

Fig. 2. Surface topography $(55 \mathrm{x} 45 \mathrm{~km})$ and observation sites used. (AGH: Aghdasiyeh, DOS: Doshantapeh, GEO: Geophysics (including Sodar observation), MEH: Mehrabad (including Radiosonde observation), CHI: Chitgar station, T1: Resalat tower and T2: Tehransar tower. 


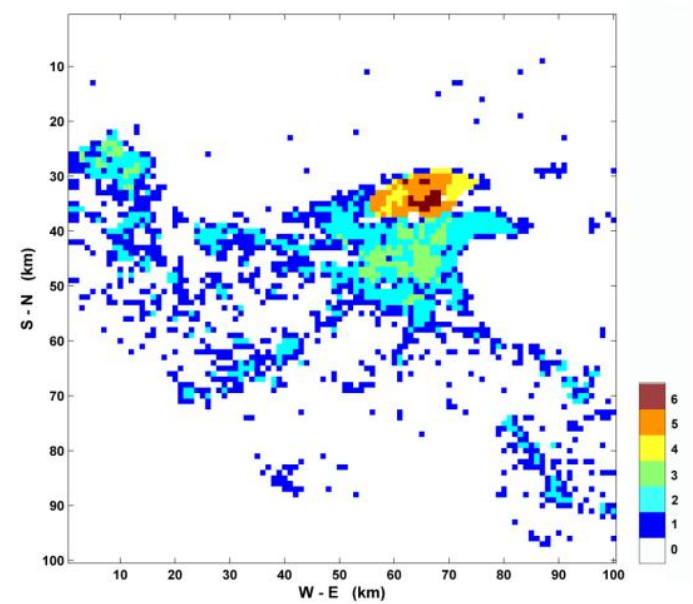

Table 1 Simple morphology classifications used for UCP

\begin{tabular}{|c|c|c|}
\hline $\begin{array}{l}\text { Urban } \\
\text { Sub- } \\
\text { categories }\end{array}$ & $\begin{array}{l}\text { Mean } \\
\text { height }\end{array}$ & $\begin{array}{l}\text { Roof fraction of } \\
\text { the artificial } \\
\text { surfaces }\end{array}$ \\
\hline 1 & 10 & 0.35 \\
\hline 2 & 10 & 0.40 \\
\hline 3 & 10 & 0.45 \\
\hline 4 & 22 & 0.35 \\
\hline 5 & 22 & 0.40 \\
\hline 6 & 22 & 0.45 \\
\hline
\end{tabular}

Fig. 3. Grid cells designated as urban areas (by land use) are shaded in Tehran basin.

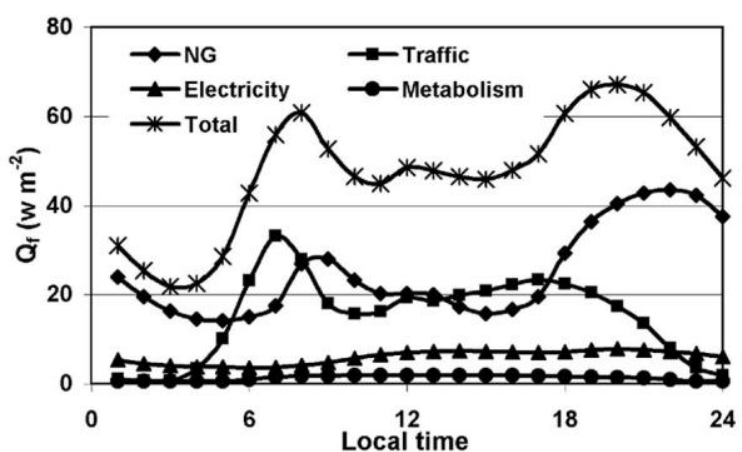

(a)

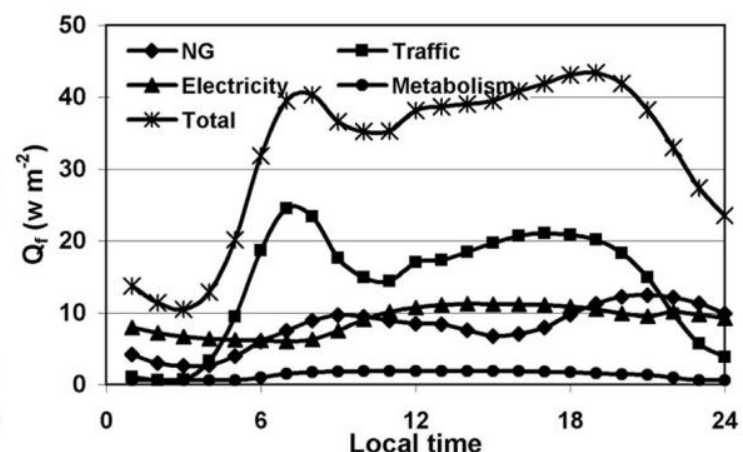

(b)

Fig. 4. Representative city-scale $\mathrm{Q}_{\mathrm{f}}$ profile and its components for winter (left) and summer (right) in Tehran urban area (2004-2005).

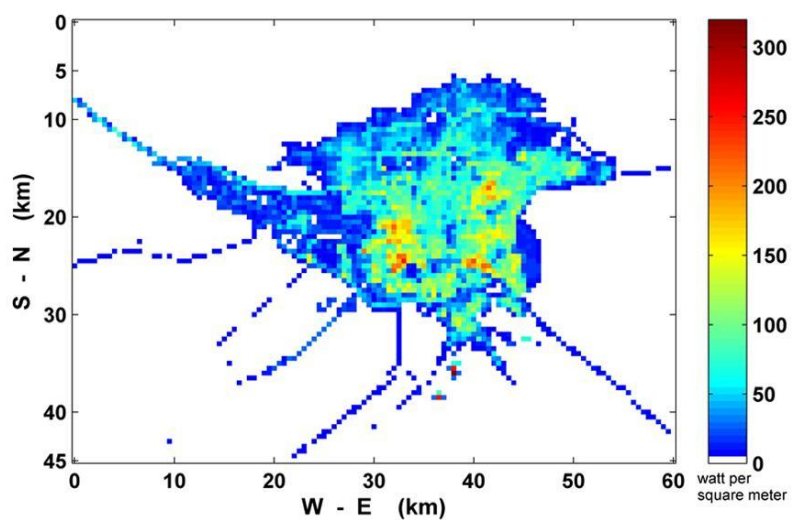

(a)

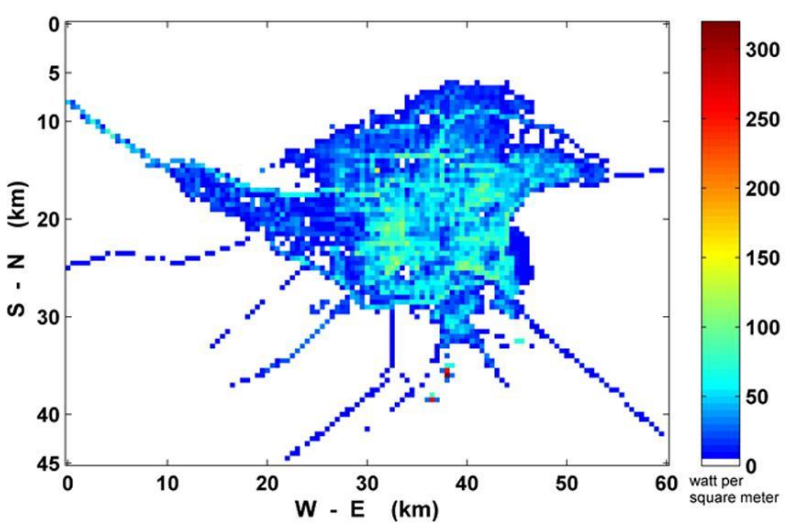

(b)

Fig. 5. Daily average $Q_{f}$ patterns released near surface (first 40 meters) relate to workdays in winter (a), and summer (b) in 2004-2005 period. 


\section{CASE Study ANd Results}

In this study, we selected November and December 2005 as two-month study period and we focus on the episode of 2 to 7 December where high concentrations of pollutants were observed and here we have selected only simulations during the period of UTC 12:00 12/4/2005 12:00 12/7/2005. During 5-7 December 2002, air pollution concentration (e.g. up to $30 \mathrm{ppm}$ and $225 \mu \mathrm{g} . \mathrm{m}^{-}$ ${ }^{3}$ for CO and PM10 respectively) was severely exceeded from standard levels (e.g. equal to $9 \mathrm{ppm}$ eight-hour averaged and $150 \mu \mathrm{g} . \mathrm{m}^{-3}$ diurnal averaged, for $\mathrm{CO}$ and PM10 respectively) in downtown area of Tehran. The first 5 hours were used as the model spin-up period and were not included in subsequent analyses. Results are presented for December 5 th.

Clear skies and light crest-level $(700 \mathrm{hPa})$ winds prevailed during the study period, allowing thermally driven winds to develop. At $500 \mathrm{hPa}$, the geopotential height gradient indicates large-scale zonal flow over Iran with a weak short-wave ridge moving eastward behind an exiting short-wave trough. At $700 \mathrm{hPa}$, relative humidities are low $(<60 \%)$ and winds are light $\left(<5 \mathrm{~m} \mathrm{~s}^{-1}\right)$ and northwesterly with little or no temperature advection.

\subsection{Analyses and Validation of the Vertical and Diurnal Profiles}

Fig. 6 compares the $10-\mathrm{m}$ wind speed and wind direction simulated by the three configurations with measurements in Resalat station (tower 1: T1) and in Tehransar station (tower 2: T2) during 5 December 2005. Resalat and Tehransar stations are located in west and east parts of the Tehran city, respectively.

The RA-SLAB simulation generally overpredicts the wind speeds (especially in Resalat station) whereas the DA-SM2-U with "Qf: On" simulates wind speeds that match the observations slightly better. The simulated and observed 24-h evolutions of wind direction represent daily and nightly regimes. The wind direction simulated by the RA-SLAB shows shorter period for anabatic flows than observations. It means that upslope winds start later and reverse sooner in this simulation than in the observations, whereas the "DA-SM2-U $\mathrm{Q}_{\mathrm{f}:}$ On" simulates anabatic regime slightly better.

The RA-SLAB simulation generally overpredicts the wind speeds (especially in Resalat station) whereas the DA-SM2-U with "Qf: On" simulates wind speeds that match the observations slightly better. The simulated and observed 24-h evolutions of wind direction represent daily and nightly regimes. The wind direction simulated by the RA-SLAB shows shorter period for anabatic flows than observations. It means that upslope winds start later and reverse sooner in this simulation than in the observations, whereas the "DA-SM2-U $Q_{\mathrm{f}:}$ On" simulates anabatic regime slightly better.

VWD allows for the total horizontal wind to be evaluated using a single statistic, and it is defined by Stauffer and Seaman (1990) as

$V W D=\left[\left(U-U_{o}\right)^{2}+\left(V-V_{o}\right)^{2}\right]^{0.5}$

where $U$ and $V$ are the horizontal wind components and the subscript $\mathrm{O}$ refers to the observed values.

Several statistical measures are also computed using the observations. Willmott (1982) suggests a variety of measures to quantify model performance (see Table 2, that statistical parameters are provided). Fig. 7 shows time series of rms for vector wind difference (VWD) calculated only for the five urban sites for 5 December 2005. The result in "DA-SM2-U Qf: On" can be attributed to the ability to simulate better low level wind characteristics, as well as the improved intensity and time variation of local regimes, by specifically including urban effects. For the VWD, during nighttime hours, "DA-SM2-U Q: On" is nearly the best of the three cases. There is no clear trend in verification over day and "DASM2-U Q $Q_{\mathrm{f}}$ : On" is best at various hours except for two hours. Results are similar during night time. In fact, "DA-SM2-U Q: On" maintains a VWD rms of less than $1.71 \mathrm{~ms}^{-1}$. When both fields are considered together, "DA-SM2-U Q $\mathrm{Q}_{\mathrm{f}}$ : On" outperforms the simulations of "DA-SM2-U Q: Off" and "RA-SLAB Q: Off" overall for the urban sites. Table 2 contains the aggregate $24-\mathrm{h}$ statistics for all stations (see Fig. 2) during 5-6 December 2005. The "DA-SM2-U Q $\mathrm{Q}_{\mathrm{f}}$ On" is consistently superior to "DA-SM2-U Q $\mathrm{Q}_{\mathrm{f}}$ Off" and "RA-SLAB $\mathrm{Q}_{\mathrm{f}}$ : Off" in all statistical categories of wind. The MEAN ERR for wind speed shows that "RA-SLAB $\mathrm{Q}_{\mathrm{f}}$ : Off" tends to overpredict and "DA-SM2-U Q $\mathrm{Q}_{\mathrm{f}}$ Off" tends to underpredict wind speed, whereas "DA-SM2-U Q: On" slightly underpredicts wind speed. There is an improvement of $0.3-1.5 \mathrm{~m} \mathrm{~ms}^{-1}$ in MAE with "DA-SM2$U Q_{f}$ : On". The IOA in "DA-SM2-U Q $Q_{f}$ On" is higher, and the rmse is lower by $0.3-0.6 \mathrm{~ms}^{-1}$. SYS is much lower in "DA-SM2-U Q: On" than "DA-SM2-U Q: Off" and "RA-SLAB $Q_{f}$ : Off". For the mean VWD, during all observations, "DA-SM2-U $\mathrm{Q}_{\mathrm{f}}$ : On" is the best of the three cases and the mean VWD is lower by $0.37-0.78 \mathrm{~m}$ $\mathrm{s}^{-1}$. 

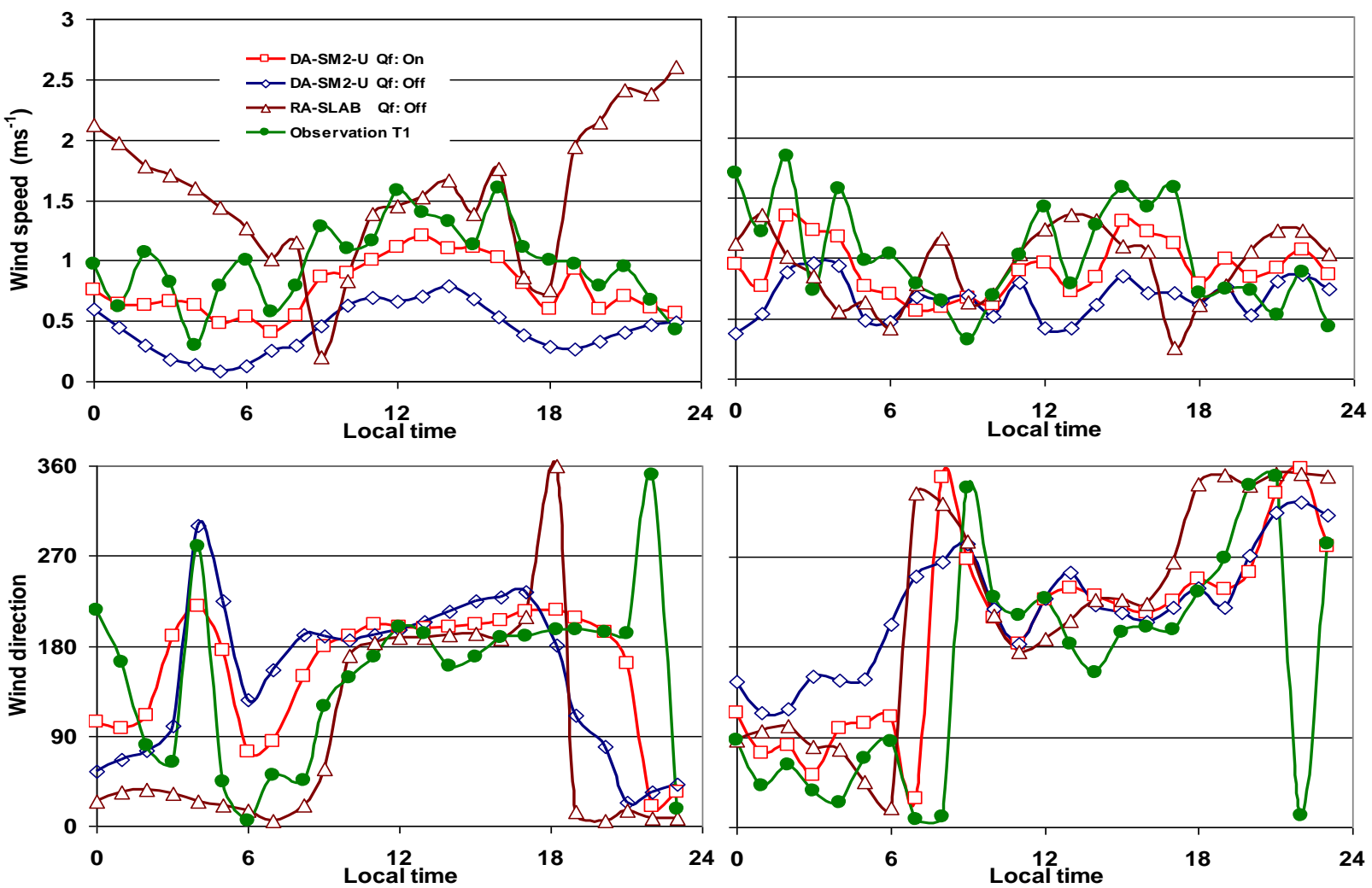

Fig. 6. Comparison between the observed and simulated wind speed and wind direction at $10 \mathrm{~m}$ in Resalat (tower 1 : T1) and Tehransar station (tower 2: T2) during 5th December 2005.

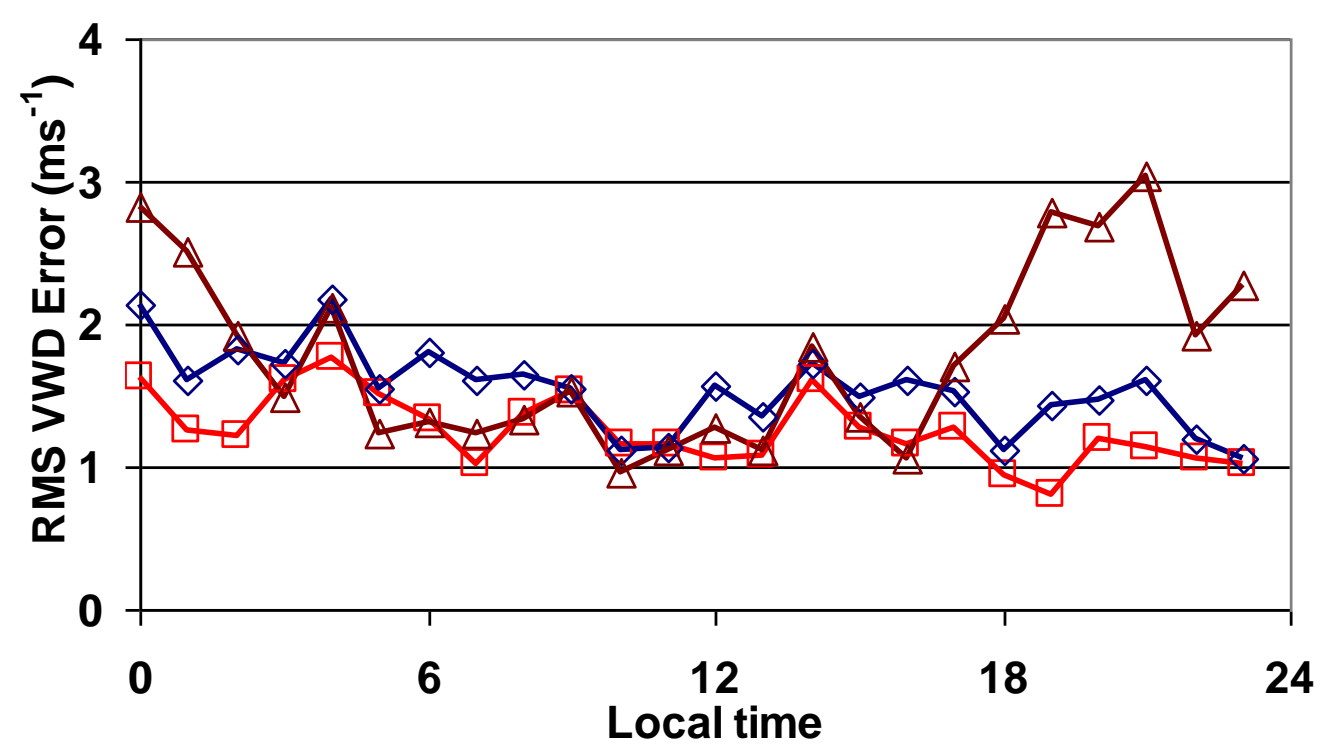

Fig. 7. Time series of VWD rms for urban sites (as shown in Fig. 2), during 5 December 2005. 
H. Malakooti and A. A. Bidokhti / JAFM, Vol. 7, No. 2, pp. 299-313, 2014.
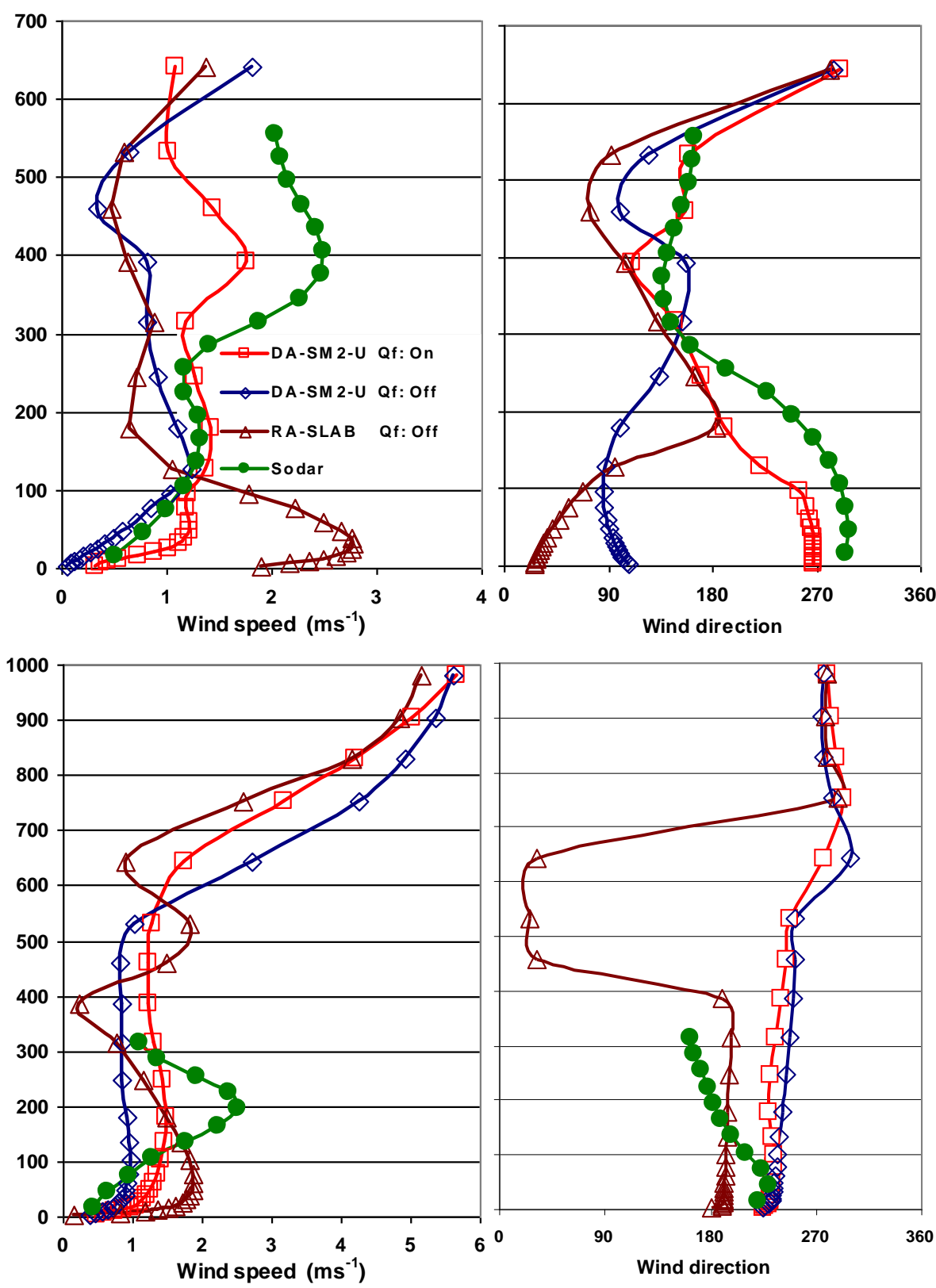

Fig. 8. Vertical profiles of wind speed and wind direction in urban point (Geophysics station: average in $2 \times 2 \mathrm{~km}^{2}$, average building height: $22 \mathrm{~m}$ ) at $2 \mathrm{am}$ (top) and $2 \mathrm{pm}$ (down) 5th December 2005, for the three simulations, "DA-SM2-U Q: On", "DA-SM2-U Q: Off" and "RA-SLAB Q: Off".

Table 2 Aggregate 24-h statistics for wind during 5-6 December 2005 for all urban sites

\begin{tabular}{|lc|c|c|c|c|c|c|c|c|c|}
\hline & & \multicolumn{9}{|c|}{ Wind statistics } \\
\cline { 2 - 11 } & & $\begin{array}{l}\text { MAE } \\
\left(\mathrm{ms}^{-1}\right)\end{array}$ & $\begin{array}{l}\text { ME } \\
\left(\mathrm{ms}^{-1}\right)\end{array}$ & IOA & $\begin{array}{l}\text { Rmse } \\
\left(\mathrm{ms}^{-1}\right)\end{array}$ & $\begin{array}{l}\text { Rmses } \\
\left(\mathrm{ms}^{-1}\right)\end{array}$ & $\begin{array}{l}\text { Rmseu } \\
\left(\mathrm{ms}^{-1}\right)\end{array}$ & SYS & UNSYS & $\begin{array}{l}\text { VWD } \\
\left(\mathrm{ms}^{-1}\right)\end{array}$ \\
\hline $\begin{array}{l}\text { DA-SM2-U } \\
\text { On }\end{array}$ & $\mathbf{Q}_{\mathbf{f}}:$ & 0.97 & -0.16 & 0.72 & 1.26 & 0.78 & 0.99 & 0.38 & 0.62 & 1.14 \\
\hline $\begin{array}{l}\text { DA-SM2-U } \\
\text { Off }\end{array}$ & $\mathbf{Q}_{\mathbf{f}}:$ & 1.29 & -0.61 & 0.61 & 1.54 & 1.01 & 1.16 & 0.43 & 0.57 & 1.51 \\
\hline $\begin{array}{l}\text { RA-SLAB } \\
\text { Off }\end{array}$ & $\mathbf{Q}_{\mathbf{f}}:$ & 1.43 & 1.19 & 0.56 & 1.88 & 1.43 & 1.22 & 0.58 & 0.42 & 1.92 \\
\hline
\end{tabular}


These improvements in wind fields in "DA-SM2-U $Q_{f}$ : On", are important for simulating the transport and production of air pollutants through urban areas. When the mixing height and stability improvements are also considered for air-quality modeling at this scale, the "DA-SM2-U Q: On" might be better than the roughness approach "RA-SLAB Q: Off". Both simulation and sodar observations show a vertical structure of the flow with two layers during the nights. DA-SM2-U simulations do not show strong stratification in PBL flows that can be due to the building drag and thus more mixing in PBL. The RA approach overestimates wind speed in the first $100 \mathrm{~m}$ of PBL and its wind direction shows highly imprecise results (see Fig. 8). The thickness of the first layer of flow is about 250 and 350 $\mathrm{m}$ during the night and the day, respectively.

\subsection{Wind Flow near the ground}

The wind field near the ground is particularly dependent on the structure of the urban canopies and on their parameterization, as well as on the heat fluxes emitted by the canopy elements. Just above the canopy, this field is influenced by the heat and momentum fluxes from the canopies. Their correct simulation is critical since it is principally at this level that the pollutants arising from the canopy are dispersed toward neighboring areas. In this section, the wind fields at $10 \mathrm{~m}$ above the ground surface simulated by three configurations are discussed. In order to analyze the wind field in the Tehran region, we focus on a part of the computational domain that includes urban area and surrounding valleys and mountains (see Fig. 2). This area represents a region with a very complex wind regime, where an interaction between UHI circulation and mountain/valley winds exists. It is expected that fields simulated with "DASM2-U Q $\mathrm{Q}_{\mathrm{f}}$ On" show interaction among UHI and mountain-valley circulations better than other configurations. Fig. 9 represents the simulated wind fields at $10 \mathrm{~m}$ above the ground in Tehran region at 4 am and $4 \mathrm{pm}$ on December $5^{\text {th }}$, 2005. The results demonstrate the model's ability to simulate the interaction between UHI and mountain-valley flows in this area. The wind field simulations by the RA-SLAB approach show that, in the main part of the city katabatic winds are dominated with one NW-SE wind front in southwest of city during the night. This approach represents anabatic winds during the day with a similar wind front between local wind and general wind regime. As discussed above, wind speeds simulated with this configuration are overpredicted and show the same regime over the entire city in contradiction with observations. The "DA-SM2-U Q $\mathrm{Q}_{\mathrm{f}}$ Off" simulates katabatic and anabatic winds with lower speed and this flows cannot dominate the entire city. The building drag can be one of the reasons for decreasing the topographic flow intensity in Tehran area by this simulation, because the north Tehran area are characterized by higher and medium density of building canopies. The interaction between topographic flows and flows forced by UHI is more complex than obtained with the RA-SLAB results, especially during night. The wind field simulations with the "DA-SM2-U Q: On" approach, show that only the suburban part of city is dominated by topographic flows whereas the center and south of city are more affected by UHI forcing during night. It means that flows in low elevations are dominated by UHI thermal forcing. Furthermore, during the night period, the combination of the katabatic winds with the UHI is complicated by upslope flow from the south which causes an amplified UHI in this simulation. It means that cold advection induced by katabatic winds and upslope flow from the other side generates a strange UHI during the night. This convergence induced by combination of local and non local regimes is evident in wind fields simulated by "DA-SM2-U Q $\mathrm{Q}_{\mathrm{f}}$ : On" approach during night. During the night, all simulations show one local front in southwest of city that it relates to the front between two different wind regimes (local and non-local).

\subsection{Analyses of Local Circulations}

A vertical cross section along the line A-A (see Fig. 2 for location) shows the difference fields of potential temperature, vertical velocity and wind vectors in the plane of the cross section (Fig. 10). The warm anomaly over the urban areas is evident, along with enhanced southerly flow aloft. There is also a cold anomaly near the Alborz Range, associated with lower values of sensible heat flux, a result of local surface energy balance differences. As in Fig. 10, the "RA-SLAB Q: Off" simulates katabatic winds stronger than other configurations and show more stability inside PBL. The local front between this regime and non local regime is evident in the left of the plane in cross section. 

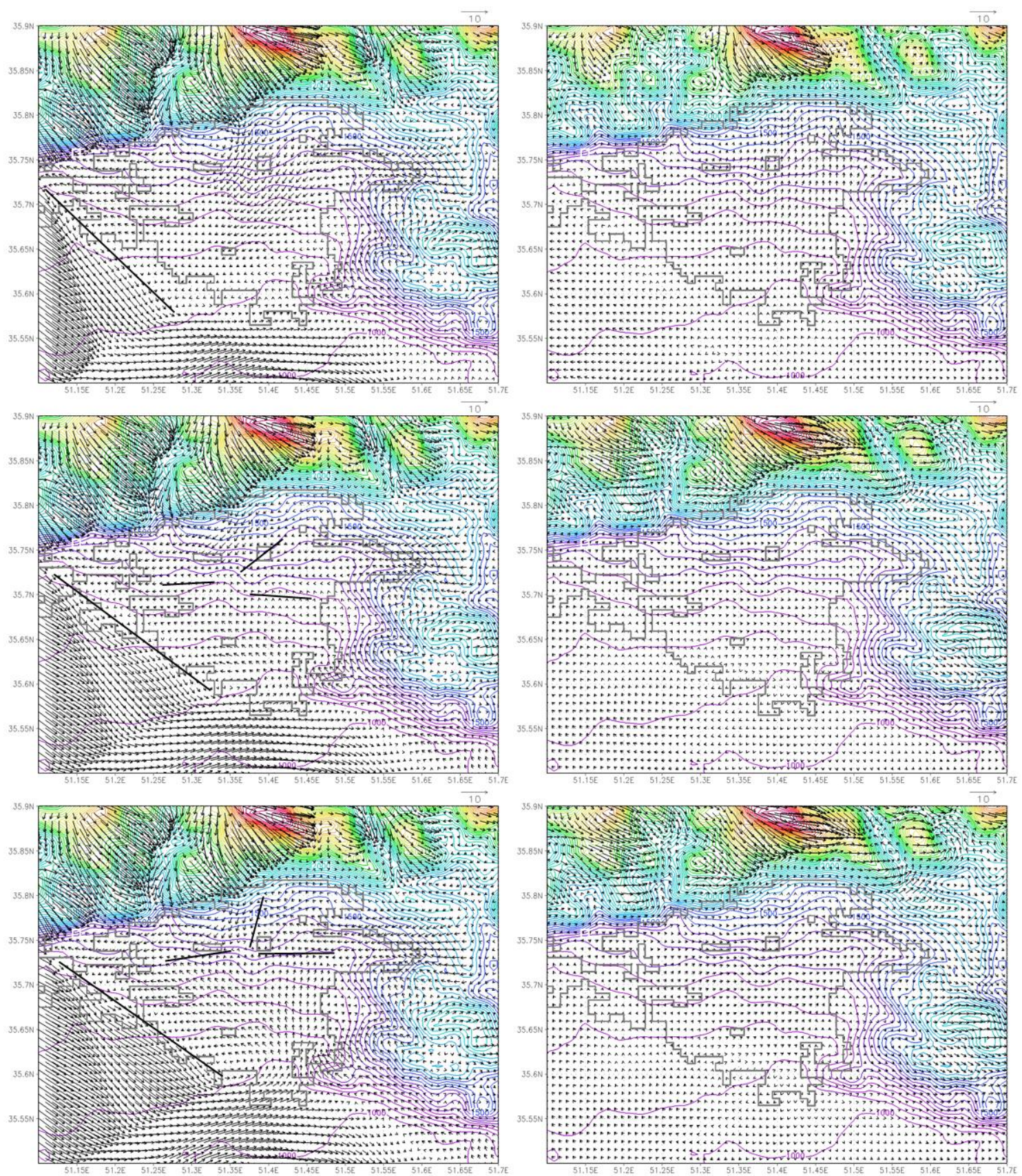

Fig. 9. Wind vector simulated by "RA-SLAB $Q_{f}$ : Off" (top), "DA-SM2-U Qf: Off" (middle) and "DA-SM2-U Qf: On" (bottom) at $10 \mathrm{~m}$ AGL at 4 am (left) and 4 pm (right) December 5th 2005. 
H. Malakooti and A. A. Bidokhti / JAFM, Vol. 7, No. 2, pp. 299-313, 2014.
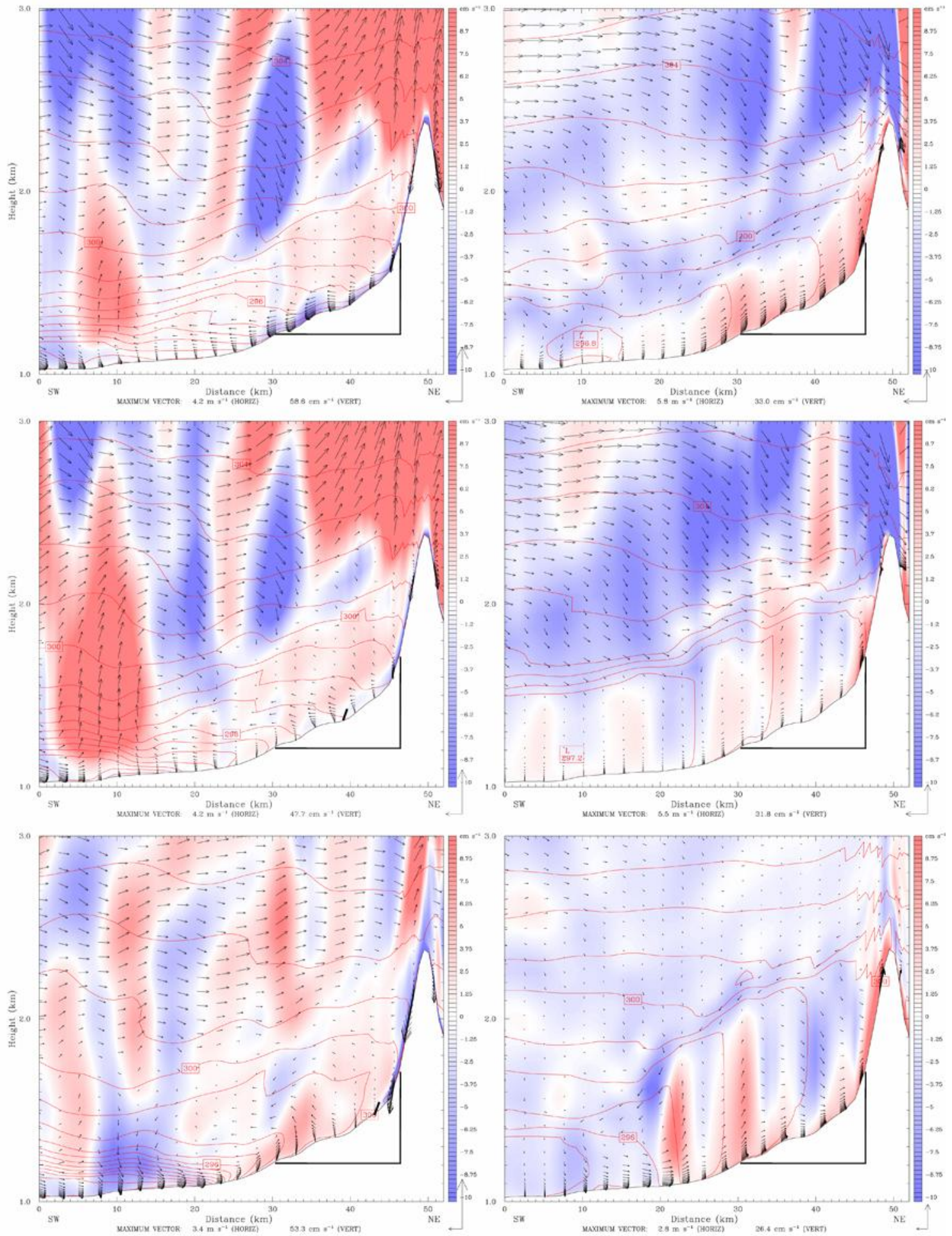

Fig. 10. Cross section along A-A of potential temperature, vertical velocity in color shading, and wind vectors simulated by "RA-SLAB Q: Off" (top), "DA-SM2-U Q: Off "(middle) and "DA-SM2-U Q: On" (bottom) at 4 am (left) and 4pm (right) December 5th 2005.

The "DA-SM2-U Qf: Off" simulates katabatic winds, but those are lighter and they do not dominate the entire city.
The local front is evident in the left of the plane similar to the "RA-SLAB Qf: Off" configuration. The simulated 


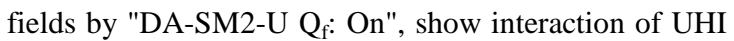
and mountain-valley flows better than other configurations, because this configuration considers urban effects much better than RA-SLAB. The katabatic winds obtained with this configuration do not enter the urban core because of the UHI forcing and a secondary front appears between upslope flow forcing by UHI and non local wind with katabatic flows. The combination of the katabatic winds from north and the upslope flow from south (Which is accompanied with a significant subsidence) with the UHI are conjoined which causes an amplified UHI in this simulation.

However, during the day (see Fig 10), anabatic winds dominate the city. The "RA-SLAB Qf: Off" simulates this regime strong and continues with thickness about $300 \mathrm{~m}$. The "DA-SM2-U Qf: Off" simulates anabatic wind but they are made lighter and they do not including any sharp front. In the "DA-SM2-U Q: On" simulations, stronger fronts appear, the left one is located between non-local winds with flow forcing by UHI and the right one is located between regime that depends on UHI forcing and anabatic regime from suburban areas.

During the day, the wind fields simulated by RA-SLAB showed subsidence in higher altitudes of the city area and near the ground in south rural part of Tehran. The DA-SM2-U wind fields show some subsidence in lower altitudes in the city area and near ground in the south sub-urban part of Tehran.

\section{Conclusions}

Sensitivity runs using MM5 in a mountainous, semi-arid environment have identified urban surface characteristics and its dynamic and thermodynamic effects as being very important in simulation of local PBL structure and wind regimes.

The analysis of vertical wind profiles inside the urban RSL has shown a realistic behavior of "DA-SM2-U Q: On", consistent with observed data in urban areas.

Within the canopies, the DA-SM2-U meteorological fields seem well simulated following the canopy morphology: decrease of the wind speed inside the dense canopies, skirting of the flow around the canopy blocks, warmer air inside the urban canopy especially during the night.

Tehran PBL structure is strongly affected by topographic and heat island forcing and shows a multi layer structure. Urban roughness and also its thermodynamic effects induce convergence and complex local circulations in this region. These local circulations could not be simulated well if a model does not take into account urban forcing. The DA-SM2-U wind fields show that the urban area has a significant forcing in thermal driving regimes in this area. However, we recognize that strong conclusions about interaction between local thermal diving's flows cannot be drawn from a single case study.

The results indicate that roughness approach (RA) is unsatisfactory and using a detail UCP may have significant improvements for meteorological modeling at neighborhood scales in this area.

In particular, the DA-SM2-U tends to improve simulations of wind regimes characteristics in and downstream of urban areas, all of which affect air-quality modeling.

\section{ACKNOWLEDGEMENTS}

Let me begin by expressing my thanks to Dr. Christian Seigneur for the high standard of his guidance. I wish to acknowledge the Islamic Republic of Iran Meteorological Organization (IRIMO), Tehran air pollution control company (AQCC), Institute of Geophysics (University of Tehran), Iran Department of environment (DOE), Tehran Gas Company (TGC), Tehran Province Regional Electricity Company (TREC)'s Consumption Management Administration for providing essential data. Funding was provided by CEREA, Joint Laboratory École des Ponts ParisTech (Université Paris-Est) /EDF R\&D and University of Hormozgan (Bandar Abbas, Iran).

\section{REFERENCES}

Atkinson, B.W. (1981). Meso-scale Atmospheric Circulations. Academic Press, UK.

Atkinson, B.W. (2003). Numerical modeling of urban heat-island intensity, Boundary-Layer Meteorology, $109,285-310$

Bidokhti, A.A. and M. Noroozi, (2004). "A physical model for the layered structure of a density driven flow over a slop", Proceedings of 10th Asian Fluid Mechanics Congress, Peradeniya, Sri Lanka, May.

Brown, M.J. (2000). Urban parameterizations for mesoscale meteorological models. Mesoscale Atmospheric Dispersion, Z. Boybeyi, Ed., Wessex Press, UK.

Dupont, S. and P.G. Mestayer (2006). Parameterization of the Urban Energy Budget with the Submesoscale Soil Model. Journal of Applied Meteorology and Climatology 45, 1744-1765.

Dupont, S., P.G. Mestayer and E. Guilloteau (2006). Parameterization of the Urban Water Budget with the Submesoscale Soil Model. Journal of Applied Meteorology and Climatology 45, 624- 648.

Dupont, S., T.L. Otte and J.K.S. Ching (2004). Simulation of meteorological fields within and above urban and rural canopies with a mesoscale model (MM5). Boundary-Layer Meteorology 113, $111-158$

Grell, G.A., J. Dudhia, and D.R. Stauffer, (1994). A description of the fifth-generation Penn State/NCAR mesoscale model (MM5). NCAR Technical Note, NCAR/TN-398+STR, 117 pp. 
H. Malakooti and A. A. Bidokhti / JAFM, Vol. 7, No. 2, pp. 299-313, 2014.

Grimmond, C.S.B. (1992). The suburban energy balance: methodological considerations and results for a midlatitudes west Coast City under winter and spring conditions, International Journal of Climatology 12, 481-497.

JICA project report (1997). The Study on an Integrated Master Plan for Air Pollution Control in the Greater Tehran Area in the Islamic Republic of Iran, $816 \mathrm{pp}$.

Khan, S.M. and R.W. Simpson (2001). Effect of heat island on the meteorology of a complex urban airshed. Boundary-Layer Meteorology 100, 487506.

Kondo, H. and Y. Kikegawa (2003).Temperature variation in the urban canopy with anthropogenic energy use. Pure and Applied Geophysics 160, 317324.

Lacser A. and T.L. Otte (2002). "Implementation of an Urban Canopy Parameterization in MM5", Proceedings of 4th Symposium on Urban Environment, American Meteorological Society, Norfolk, US, May.

Martilli, A., A. Clappier and M. W. Rotach (2002). An urban surface exchange parameterization for mesoscale models. Boundary-Layer Meteorology 104, 261-304.

Masson, V. (2000). A physically-based scheme for the urban energy budget. Boundary-Layer Meteorology 94, 357-397.

Monti, P., H.J.S. Fernando, M. Princevac, W.C. Chan, T.A. Kowalewski, and E.R. Pardyjak (2002). Observations of flow and turbulence in the nocturnal boundary layer over a slope. Journal of the Atmospheric Sciences 59, 2513-2534.
Oke, T.R. (1982). The energetic basis of the urban heat island. The Quarterly Journal of the Royal Meteorological Society 108, 1-24.

Reisner, J., R.J. Rasmussen, and R.T. Bruintjes (1998). Explicit forecasting of supercooled liquid water in winter storms using the MM5 mesoscale model. The Quarterly Journal of the Royal Meteorological Society 124B, 1071-1107.

Sailor, D.J. and L. Lu (2004). A top-down methodology for developing diurnal and seasonal anthropogenic heating profiles for urban areas. Atmospheric Environment 38, 2737-2748.

Sailor, D.J., J.N. Rosen and J.R. Munoz (1998). Natural Gas Consumption and Climate: a Comprehensive Set of Predictive State-Level Models for the United States. Energy-the International Journal 23, 91103.

Shafran, P.C., N.L. Seaman and G.A. Gayno (2000). Evaluation of numerical predictions of boundary layer structure during the Lake Michigan Ozone Study. Journal of Applied Meteorology 39, 412426.

Stauffer D.R. and N.L. Seaman (1994). Multiscale fourdimensional data assimilation. Journal of Applied Meteorology 33, 416-434.

Stauffer, D.R. and N.L. Seaman (1990). Use of fourdimensional data assimilation in a limited-area mesoscale model. Part I: Experiments with synoptic-scale data, Monthly Weather Review, 118, $1250-1277$.

Ueno, T., R. Inada, O. Saeki and K. Tsuji (2006). Effectiveness of an energy-consumption information system for residential buildings. Applied Energy 83, 868-883.

Whiteman, C.D. (2000). Mountain Meteorology: Fundamentals and Applications, Oxford University Press, US. 